\section{Inactivation of Factor XII Active Fragment in Normal Plasma Predominant Role of Cí-Inhibitor}

\author{
Ariane de Agostini, Henri R. Lijnen, Robin A. Pixley, \\ Robert W. Colman, and Marc Schapira \\ Division de Rhumatologie, Hôpital Cantonal Universitaire, \\ Genève, Switzerland; Center for Thrombosis and Vascular \\ Research, Department of Medical Research, Katholieke \\ Universiteit Leuven, Leuven, Belgium; and Hematology-Oncology \\ Section, Department of Medicine, and Thrombosis Research \\ Center, Temple University School of Medicine, \\ Philadelphia, Pennsylvania 19140
}

Cî-inhibitor, whereas $26 \%$ of the enzyme formed complexes with $\alpha_{2}$-antiplasmin and antithrombin III. Furthermore, $42 \%$ of the labeled enzyme was still complexed with $\mathrm{C} \overline{1}$-inhibitor when ${ }^{125} \mathrm{I}$-Factor XII was inactivated in hereditary angioedema plasma that contained $32 \%$ of functional Cí-inhibitor. This study quantitatively demonstrates the dominant role of $\mathrm{C} \overline{1}$-inhibitor in the inactivation of Factor XIIf in the plasma milieu.

\section{Introduction}

The active fragment derived from Factor XII (Factor XIIf)' ${ }^{1}$ is a serine protease $\left(M_{\mathrm{r}} 28,000\right)$ that results from proteolytic cleavage of Factor XII. This cleavage can occur on a surface, during contact activation of normal plasma (1-3), or in solution, as a consequence of Factor XII digestion by various proteolytic enzymes, including plasmin and plasma kallikrein (3-5). In vitro, Factor XIIf is a potent liquid-phase activator of plasma prekallikrein (6-7), which also activates Factor VII (8), plasminogen (9), and the first component of the classical pathway of complement $(10,11)$. However, Factor XIIf exhibits minimal clotpromoting activity $(6,7)$. In vivo, severe arterial hypotension was observed after the administration to surgical patients of plasma protein fraction containing Factor XIIf (12). This observation suggested that the circulatory collapse seen in these patients depended upon Factor XIIf-mediated plasma prekallikrein activation (12). Direct support for this suggestion was recently obtained by the observation that increased plasma bradykinin levels were observed in patients who presented arterial hypotension as a result of the administration of plasma protein fraction that contained Factor XIIf (13).

Studies in purified systems have shown that Factor XIIf is

1. Abbreviations used in this paper: DFP, diisopropylfluorophosphate; Factor XIIf, active fragment derived from Factor XII; p-NPGB, p-nitrophenyl p'-guanidinobenzoate $\mathrm{HCl}$; SDS-PAGE, sodium dodecyl sulfate polyacrylamide gel electrophoresis. 
inactivated by several plasma protease inhibitors, including $C \overline{1}-$ inhibitor, antithrombin III, and $\alpha_{2}$-antiplasmin (14-18). Immunochemical studies have indicated that the incubation of Factor XIIf with normal plasma resulted in the formation of a complex involving Factor XIIf and Cī-inhibitor (19). Although these investigations demonstrate that at least three plasma protease inhibitors can inactivate Factor XIIf, they do not provide a quantitative description of the factors responsible for Factor XIIf inactivation in the plasma milieu. Such an analysis is reported in this manuscript.

\section{Methods}

Materials. Dextran sulfate, CNBr-activated Sepharose 4B, quaternary aminoethyl-Sephadex A-50, Sephadex G-25 and G-75, and heparinSepharose CL-6B (Pharmacia Fine Chemicals, Uppsala, Sweden); trypsin$\mathrm{N}$-tosyl-L-phenylalanine chloromethyl ketone and soybean trypsin inhibitor (Millipore Corp., Freehold, NJ); H-D-Pro-Phe-Arg-p-nitroanilide (S-2302) (Kabi Diagnostica, Stockholm); p-nitrophenyl p'-guanidinobenzoate $\mathrm{HCl}$ ( $p$-NPGB) (Merck and Co., Inc., Darmstadt, West Germany); diisopropylfluorophosphate (DFP) (Fluka AG, Buchs, Switzerland); Bolton-Hunter reagent (Amersham Corp., Amersham, England); antiserum to $\mathrm{C} \overline{1}$-inhibitor and antithrombin III (Behringwerke AG, Marburg, West Germany) and to $\alpha_{2}$-antiplasmin (Nordic Immunological Laboratories, Tilburg, The Netherlands) were purchased from the designated supplier.

Fresh plasma anticoagulated with citrate phosphate dextrose adenine (CPDA-1; Baxter Travenol Laboratories, Castlebar, Ireland) and generously supplied by the Geneva Blood Center (Dr. P. A. Miescher) was used for protein purification. All other plasma samples were prepared by adding 9 vol blood to 1 vol $0.11 \mathrm{M}$ sodium citrate. Citrated blood was then centrifuged at $3,000 \mathrm{~g}$ for $15 \mathrm{~min}$ at $4^{\circ} \mathrm{C}$. Thereafter, plasma samples were kept frozen at $-70^{\circ} \mathrm{C}$ until use. The reference plasma pool was obtained by mixing plasma from 80 healthy blood donors (a gift from Dr. F. Bachmann, Centre Hospitalier Universitaire Vaudois, Lausanne, Switzerland). Plasma partially deficient in $\mathrm{C} \overline{1}$-inhibitor was obtained from an individual with classical hereditary angioedema. Functional and antigenic levels of $\mathrm{C} \bar{l}$-inhibitor in this plasma were, respectively, 32 and $13 \%$ of the levels measured in the reference plasma pool (20). For some experiments, hereditary angioedema plasma was pretreated with an antiserum to $C \bar{l}$-inhibitor at a concentration known to immunoprecipitate all the $C \overline{1}$-inhibitor contained in the same volume of normal plasma. Prekallikrein-deficient plasma was obtained from Dr. C. F. Abildgaard (University of California, Davis, Medical Center, Sacramento, CA). The levels of both functional and antigenic $\mathrm{C} \bar{l}$-inhibitor in prekallikrein-deficient plasma were $140 \%$ of the levels measured in the reference plasma pool. For some kinetic studies, prekallikrein-deficient plasma was depleted of $\mathrm{C} \overline{1}$-inhibitor by immunoaffinity chromatography on $\mathrm{CNBr}$-activated Sepharose 4B to which immunopurified antibodies to $C \bar{l}$-inhibitor had been covalently linked (21). In this plasma, $C \overline{1}$ inhibitor, antithrombin III, and $\alpha_{2}$-antiplasmin were, respectively, $<5$, 54 , and $74 \%$ of the levels observed in native prekallikrein-deficient plasma, as assessed by radial immunodiffusion (22). Furthermore, this plasma contained $<5 \%$ of functional Cí-inhibitor (20). $\alpha_{2}$-Antiplasmin-depleted plasma was prepared by immunoadsorption of normal plasma with purified anti- $\alpha_{2}$-antiplasmin antibodies covalently coupled to an agarose matrix (23). This plasma contained $<2 \%$ of the $\alpha_{2}$-antiplasmin level of normal plasma. For some experiments, normal plasma and $\alpha_{2}$-anti- plasmin-depleted plasma were made deficient of antithrombin III by affinity chromatography on heparin-Sepharose. This treatment resulted in a $>80 \%$ reduction of immunoreactive antithrombin III, as assessed by double-diffusion analysis (22).

Preparation of proteins. Factor XIIf was prepared using a modification of a previously described method (24). Plasma $(210 \mathrm{ml})$ was activated by the addition of acetone $(53 \mathrm{ml})$ and dextran sulfate $(65 \mathrm{mg})$ for 30 min at $23^{\circ} \mathrm{C}$. This mixture was dialyzed for $16 \mathrm{~h}$ against tap water and centrifuged at $10^{4} \mathrm{~g}$ for $15 \mathrm{~min}$ at $4^{\circ} \mathrm{C}$. The supernatant was collected and its $\mathrm{pH}$ was adjusted to 8.0 with $0.5 \mathrm{M}$ Tris-base. The activated plasma was applied to a QAE Sephadex A-50 column $(2.5 \times 75 \mathrm{~cm})$ equilibrated with $50 \mathrm{mM}$ Tris- $\mathrm{HCl}, \mathrm{pH} 8.0$. After extensive washing with the starting buffer, a gradient of $2,500 \mathrm{ml}$ to a limit of $0.6 \mathrm{M} \mathrm{NaCl}$ in the same buffer was applied. The fractions whose conductivity ranged from 11 to $17 \mathrm{mmho}$ exhibited prekallikrein-activating activity when assayed on $\mathrm{CHCl}_{3}$-treated plasma (25). These fractions were concentrated in an ultrafiltration unit (Amicon Corp., Scientific Systems Div., Danvers, MA) by using a PM 10 membrane. The concentrated material was gel filtered on a Sephadex G-25 column $(5 \times 90 \mathrm{~cm})$, equilibrated with 10 $\mathrm{mM}$ ammonium acetate, $\mathrm{pH} 7.0$, and lyophilized. This material was dissolved in $20 \mathrm{mM}$ Tris- $\mathrm{HCl}, \mathrm{pH} 8.0$, and gel filtered on a Sephadex G-75 column $(2.5 \times 84 \mathrm{~cm})$ equilibrated in the same buffer. The last step of the purification was a gel filtration on a Sephadex G-75 superfine column $(1.5 \times 90 \mathrm{~cm})$ equilibrated with $0.1 \mathrm{M}$ sodium phosphate buffer, pH 7.2, containing $0.15 \mathrm{M}$ sodium chloride. Factor XIIf was a single band of $M_{\mathrm{r}} 28,000$ on nonreduced sodium dodecyl sulfate polyacrylamide gel electrophoresis (SDS-PAGE). Upon reduction, Factor XIIf was a single band of $M_{\mathrm{r}} 32,000$. Factor XIIf specific activity was $17.9 \mu \mathrm{mol} /$ min per $\mathrm{mg}$, with S-2302 as the substrate and under conditions described later in this section. The catalytic efficiency of Factor XIIf on S-2302 $k_{\mathrm{cal}} / K_{\mathrm{M}}$ was $2.62 \times 10^{6} \mathrm{M}^{-1} \mathrm{~min}^{-1}$. Furthermore, incubation of Factor XIIf with purified plasma prekallikrein (26) at a 1:100 enzyme/substrate molar ratio for $15 \mathrm{~h}$ at $23^{\circ} \mathrm{C}$ resulted in the complete activation of prekallikrein to plasma kallikrein, as assessed by SDS-PAGE and kinetic analysis (26). Factor XIIf was radioiodinated with the Bolton-Hunter reagent (27). Its specific radioactivity was $0.3 \mathrm{mCi} / \mathrm{mg}$. Radioactivity was measured with gamma counter (1260 Multigamma; LKB Instruments, Inc., Gaithersburg, MD).

Cí-inhibitor was purified as described by Reboul et al. (28). The resultant preparation, $M_{\mathrm{r}} 105,000$ on reduced SDS-PAGE, was completely active, as assessed by its reactivity with purified plasma kallikrein (24).

Antithrombin III was purchased from Kabivitrum AB (Molndal, Sweden). It was a single band of $M_{\mathrm{r}} 60,000$ on reduced SDS-PAGE. The concentration of active material was established by measuring its reaction with plasma kallikrein (29).

$\alpha_{2}$-Antiplasmin was prepared using a modification (30) of the procedure described by Wiman (31). The concentration of purified $\alpha_{2}$ antiplasmin, a single band of $M_{\mathrm{r}} 65,000$ on nonreduced SDS-PAGE, was established by titration against plasmin that had been active-site titrated with $p$-NPGB (32).

$\alpha_{1}$-Antitrypsin was purified as described (33) and was a gift of Dr. H. L. James. $1 \mathrm{mg}$ of this preparation completely inhibited $0.44 \mathrm{mg}$ of trypsin that had been active-site titrated with $p$-NPGB (32). $\alpha_{1}$-Antitrypsin was a single band of $M_{\mathrm{r}} 54,000$ on reduced SDS-PAGE.

$\alpha_{2}$-Macroglobulin was prepared as reported by Sottrup-Jensen et al. (34). Since the resulting preparation exhibited some amidolytic activity on S-2302, it was treated with DFP (10 mM) and then extensively dialyzed. $\alpha_{2}$-Macroglobulin was predominantly a single band of $M_{\mathrm{r}}$ 185,000 on reduced SDS-PAGE. It was $85 \%$ active, as assessed by its 
ability to protect active site-titrated trypsin from inactivation by soybean trypsin inhibitor.

Corn trypsin inhibitor, prepared as described (35), was a gift of Dr. E. P. Kirby. This preparation was a single band of $M_{\mathrm{r}} 18,000$ on reduced SDS-PAGE.

Kinetic studies. Factor XIIf was incubated with various reagents in freshly silicone-coated glass vessels at $23^{\circ} \mathrm{C}$. Factor XIIf activity was measured by its amidolytic activity on the chromogenic substrate S-2302. A 0.6-mM solution of the substrate was prepared in $85 \mathrm{mM}$ sodium phosphate buffer, $\mathrm{pH} 7.6$, containing $127 \mathrm{mM} \mathrm{NaCl} .10 \mu \mathrm{l}$ of the solution to be tested was added to $330 \mu \mathrm{l}$ of substrate at $37^{\circ} \mathrm{C}$, and the absorbance change at $405 \mathrm{~nm}$ was continuously recorded with a 210 double beam spectrophotometer (Cary Instruments, Varian Associates, Instrument Division, Palo Alto, CA).

Electrophoretic studies and autoradiography. SDS-PAGE was performed as described by Laemmli (36), using vertical slab gels $(12 \times 16$ $\times 0.15 \mathrm{~cm})$ and a Protean double slab electrophoresis cell (Bio-Rad Laboratories, Richmond, CA). The concentration of acrylamide in the stacking gel was $3 \%$, whereas it was 8.5 or $10 \%$ in the separating gel. Electrophoresis was performed at $20-40 \mathrm{~mA} / \mathrm{gel}$ for 3-4 h. For autoradiography, the gels were exposed at $-70^{\circ} \mathrm{C}$ for $2.5-7 \mathrm{~d}$ to Typox RPL-Film NIF films (Typon AG, Burgdorf, Switzerland) using intensifying screens.

\section{Results}

Inactivation of Factor XIIf by purified plasma protease inhibitors: kinetic studies. The kinetics of inactivation of Factor XIIf amidolytic activity by various concentrations of $\mathrm{C} \overline{1}$-inhibitor, antithrombin III, and $\alpha_{2}$-antiplasmin are illustrated in Figs. 1-3. The inactivation of Factor XIIf followed pseudo-first-order kinetics when these inhibitors were in a 3.5- to 150 -fold molar excess. Pseudo-first-order rate constants, $k^{\prime}$, were obtained by dividing $\ln 2$ by the half-times of enzyme activity. $C \overline{1}$-inhibitor was a more efficient inhibitor of Factor XIIf than was antithrombin III or $\alpha_{2}$-antiplasmin. For example, $50 \%$ of Factor XIIf amidolytic activity was inactivated by $\mathrm{C} 1$-inhibitor $(2.8$ $\mu \mathrm{M}$ ) in $1.5 \mathrm{~min}$ (Fig. $1 \mathrm{f}$ ), whereas the same proportion of enzyme was inactivated in $18.8 \mathrm{~min}$ when antithrombin III was $11 \mu \mathrm{M}$ (Fig. $2 \mathrm{~b}$ ) and in $10.8 \mathrm{~min}$ when $\alpha_{2}$-antiplasmin was 10 $\mu \mathrm{M}$ (Fig. $3 d$ ). In additional experiments, Factor XIIf was incubated with $\alpha_{1}$-antitrypsin at final concentrations that ranged from 27.5 to $55 \mu \mathrm{M}$. No reduction in Factor XIIf amidolytic activity was seen after a 30 -min incubation at $23^{\circ} \mathrm{C}$ of Factor XIIf and $\alpha_{1}$-antitrypsin (not illustrated). We then investigated the interaction of Factor XIIf with $\alpha_{2}$-macroglobulin. $20 \mu \mathrm{l}$ of Factor XIIf $(1.8 \mu \mathrm{g})$ was incubated with $20 \mu \mathrm{l}$ of $\alpha_{2}$-macroglobulin $(41 \mu \mathrm{g})$ or with $20 \mu \mathrm{l}$ of buffer. After a 10-min incubation at $23^{\circ} \mathrm{C}$, these mixtures were assayed for Factor XIIf amidolytic activity. Identical activities were observed, whether Factor XIIf had been incubated with $\alpha_{2}$-macroglobulin or with buffer, indicating that Factor XIIf had not reacted with $\alpha_{2}$-macroglobulin or that $\alpha_{2}$-macroglobulin-bound Factor XIIf had the same amidolytic activity as free Factor XIIf. Since preincubation with $\alpha_{2}$-macroglobulin protected trypsin from inactivation by corn trypsin inhibitor, Factor XIIf was then incubated with $\alpha_{2}$-macroglobulin under the conditions described above. After a 10-

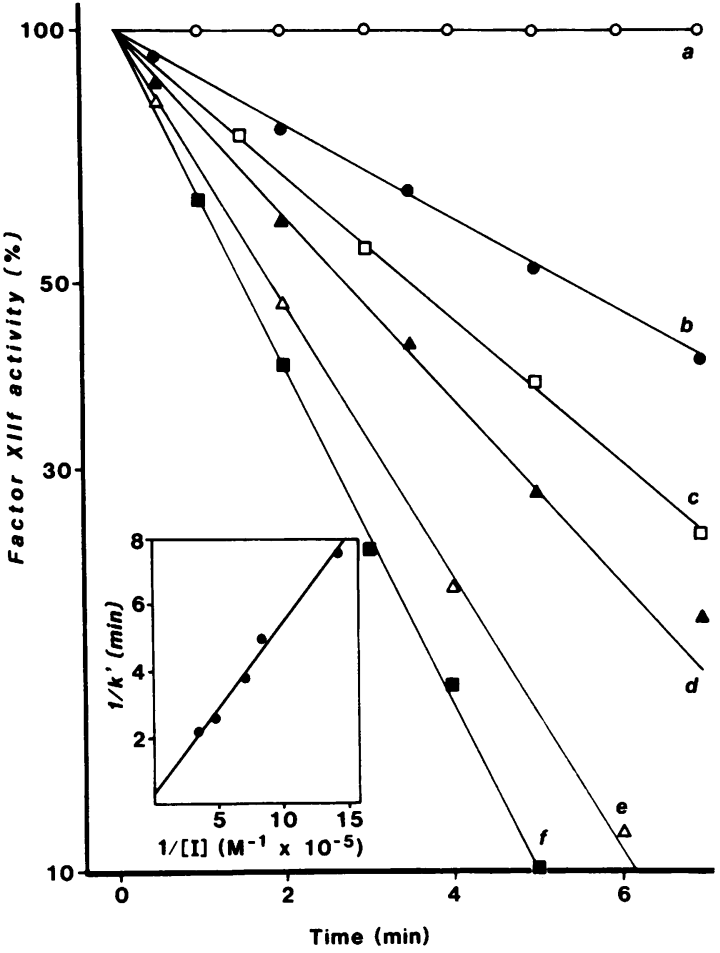

Figure 1. Kinetics of inactivation of Factor XIIf amidolytic activity by $\mathrm{C} \overline{\mathrm{I}}$-inhibitor. Factor XIIf (final concentration $0.2 \mu \mathrm{M}$ ) was incubated with various concentrations of $C \bar{l}$-inhibitor and then assayed at various times for residual amidolytic activity. $C \overline{1}$-inhibitor final concentrations were: $(a) 0 ;(b) 0.7 ;(c) 1.2 ;(d) 1.4 ;(e) 2.1$; and $(f) 2.8$ $\mu \mathrm{M}$. The inset shows a double-reciprocal plot of the pseudo-first-order rate constant and the concentration of $\mathrm{C} \overline{\text {-inhibitor }}([\mathrm{I}])$. The line drawn is a least-squares fit of the experimental points $(r=0.99)$. The equation of the line is $y=0.54 x+0.25$.

min incubation, the Factor XIIf- $\alpha_{2}$-macroglobulin mixture was supplemented either with $35 \mu$ l of corn trypsin inhibitor $(0.9$ $\mathrm{mg} / \mathrm{ml}$ ) or with $35 \mu \mathrm{l}$ of buffer. 1 min later, Factor XIIf amidolytic activity was assayed. The rate of amidolysis measured after the addition of corn trypsin inhibitor was $<0.5 \%$ of the rate observed when buffer was added to the Factor XIIf- $\alpha_{2}$-macroglobulin mixture. Thus, preincubation of Factor XIIf with $\alpha_{2}$-macroglobulin did not prevent Factor XIIf from being inactivated by corn trypsin inhibitor, indicating that no detectable reaction had occurred between Factor XIIf and $\alpha_{2}$-macroglobulin.

The kinetic constants for the inactivation of Factor XIIf by Cì-inhibitor, antithrombin III, and $\alpha_{2}$-antiplasmin were derived from double-reciprocal plots of the pseudo-first-order rate constant $k^{\prime}$ vs the inhibitor concentrations (Figs. 1-3; insets) and are listed in Table I. The second-order rate constants $k^{\prime \prime}$ for the reaction of Factor XIIf with these plasma protease inhibitors revealed that the reaction of Factor XIIf with $\mathrm{C} \overline{1}$-inhibitor was, respectively, 58 and 20 times faster than the reactions between Factor XIIf and antithrombin III or $\alpha_{2}$-antiplasmin (Table I). 


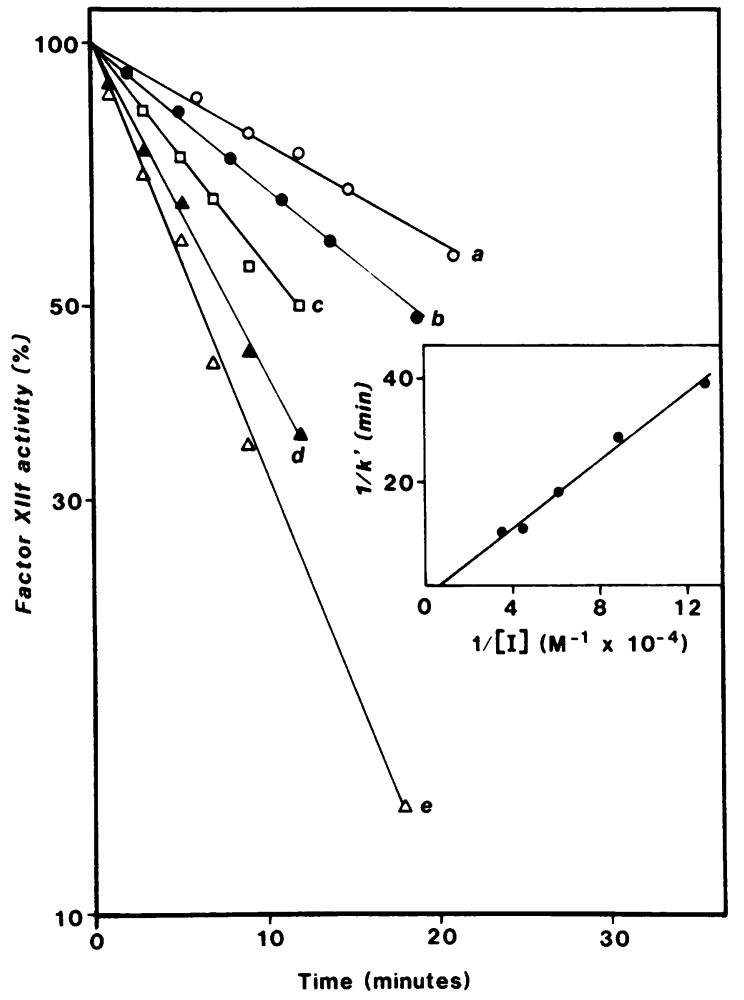

Figure 2. Kinetics of inactivation of Factor XIIf amidolytic activity by antithrombin III. Factor XIIf (final concentration $0.25 \mu \mathrm{M}$ ) was incubated with various concentrations of antithrombin III and then assayed at various times for residual amidolytic activity. Antithrombin III final concentrations were: (a) $7.7 \mu \mathrm{M}$; (b) $11 \mu \mathrm{M}$; (c) $16.5 \mu \mathrm{M}$; (d) $22 \mu \mathrm{M}$; and (e) $27.5 \mu \mathrm{M}$. The inset shows a double-reciprocal plot of the pseudo-first-order rate constant and the concentration of antithrombin III ([I]). The line drawn is a least-squares fit of the experimental points $(r=0.99)$. The equation of the line is $y=3.17 x$ -2.58 .

Furthermore, the pseudo-first-order rate constants calculated at normal plasma concentration of inhibitors suggested that in normal plasma, Cī-inhibitor would account for $93 \%$ of Factor XIIf inhibition, while antithrombin III and $\alpha_{2}$-antiplasmin would account for 4 and 3\%, respectively (Table I).

Inactivation of Factor XIIf by various plasmas: kinetic studies. The addition of Factor XIIf to plasma containing prekallikrein has been shown to result in the activation of prekallikrein to plasma kallikrein, i.e., in the formation of a species that exhibits amidolytic activity on S-2302. Thus, to evaluate the role of $\mathrm{C} \overline{1}$ inhibitor and other plasma protease inhibitors in the inactivation of Factor XIIf in the plasma milieu, we studied the kinetics of inactivation of Factor XIIf amidolytic activity by prekallikreindeficient plasma. The inactivation of Factor XIIf in a 1:3.5 dilution of the plasma followed pseudo-first-order kinetics. The rate constant for the inactivation of Factor XIIf in prekallikreindeficient plasma was $14.4 \times 10^{-2} \mathrm{~min}^{-1}$ (Fig. 4, curve $a$ ). This

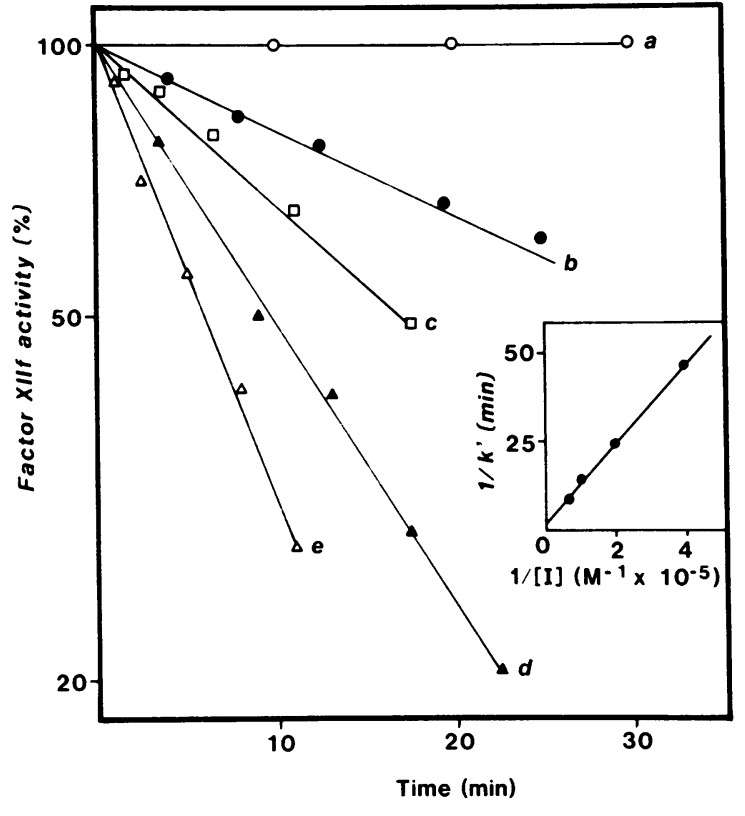

Figure 3. Kinetics of inactivation of Factor XIIf amidolytic activity by $\alpha_{2}$-antiplasmin. Factor XIIf (final concentration $0.1 \mu \mathrm{M}$ ) was incubated with various concentrations of $\alpha_{2}$-antiplasmin and then assayed at various times for residual amidolytic activity. $\alpha_{2}$-Antiplasmin final concentrations were: (a) $0 ;(b) 2.5 \mu \mathrm{M} ;(c) 5.0 \mu \mathrm{M} ;(d) 10$ $\mu \mathrm{M}$; and $(e) 15 \mu \mathrm{M}$. The inset shows a double-reciprocal plot of the pseudo-first-order rate constant and the concentration of $\alpha_{2}$-antiplas$\min ([I])$. The line drawn is a least-squares fit of the experimental points $(r=0.99)$. The equation of the line is $y=11.04 x+2.2$.

value was reduced to $1.8 \times 10^{-2} \mathrm{~min}^{-1}$ in plasma deficient in both prekallikrein and $\mathrm{C} \overline{\mathrm{l}}$-inhibitor (Fig. 4 , curve $b$ ). These kinetic experiments indicate that $C \bar{l}$-inhibitor is the predominant inhibitor of Factor XIIf in prekallikrein-deficient plasma.

Table I. Kinetic Constants for the Inactivation of Factor XIIf by CI-Inhibitor, Antithrombin III, and $\alpha_{2}$-Antiplasmin

\begin{tabular}{llll}
\hline & $\begin{array}{l}\text { Bimolecular } \\
\text { reaction rate } \\
\text { constant* }\end{array}$ & $\begin{array}{l}\text { Normal } \\
\text { plasma } \\
\text { concen- } \\
\text { tration }\end{array}$ & $\begin{array}{l}\text { Pseudo-first-order } \\
\text { inactivation rate } \\
\text { constant at normal } \\
\text { plasma* } \\
\text { concentration }\end{array}$ \\
\hline$M^{-1} \min ^{-1} \times 10^{-4}$ & $\mu M$ & $\min ^{-1} \times 10^{2}$ \\
Cí-inhibitor & 18.5 & 2.2 & 37.0 \\
Antithrombin III & 0.32 & 4.7 & 1.50 \\
$\alpha_{2}$-Antiplasmin & 0.91 & 1.1 & 0.97
\end{tabular}

* Bimolecular reaction rate constants $k^{\prime \prime}=k_{+2} / K_{\mathrm{i}}$ and pseudo-firstorder inactivation rate constants at normal plasma concentration were calculated as previously described $(29,39)$. $K_{\mathrm{i}}$, inhibitor constant.

$\ddagger$ From references 20 and 37 . 


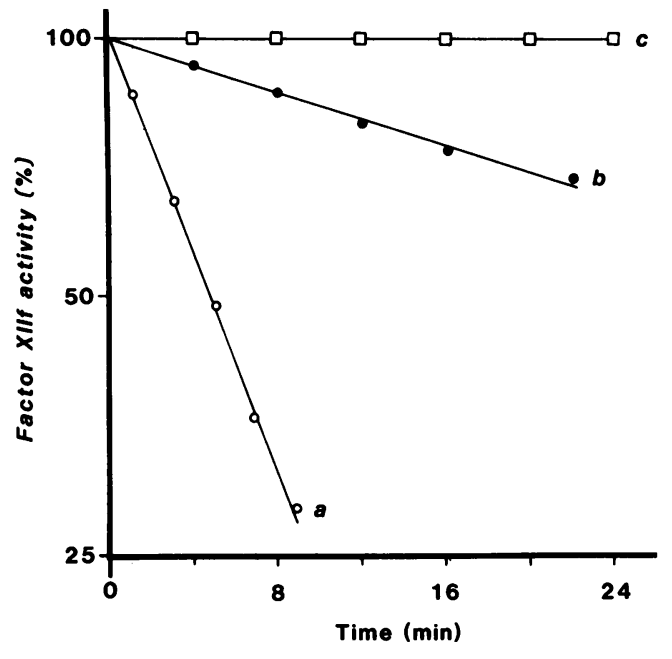

Figure 4. Kinetics of inactivation of Factor XIIf amidolytic activity by plasma. Factor XIIf (final concentration $0.1 \mu \mathrm{M}$ ) was incubated with a 1:3.5 dilution of plasma deficient in prekallikrein $(a)$ or plasma deficient in both $C \overline{1}$-inhibitor and prekallikrein $(b)$, as well as with buffer $(c)$, and then assayed at various times for residual amidolytic activity.

Inactivation of ${ }^{125}$ I-Factor XIIf by purified plasma protease inhibitors and by various plasmas: SDS-PAGE studies. To confirm the preponderant importance of $\mathrm{C} \overline{1}$-inhibitor as a Factor XIIf inhibitor in plasma, we incubated ${ }^{125} \mathrm{I}$-Factor XIIf in various plasmas and analyzed the resulting mixtures by SDS-PAGE and autoradiography for the appearance of ${ }^{125} \mathrm{I}$-Factor XIIf-inhibitor complexes. To facilitate the analysis of these studies, ${ }^{125} \mathrm{I}$-Factor XIIf was first incubated with purified plasma protease inhibitors. The incubation of ${ }^{125}$ I-Factor XIIf $\left(M_{\mathrm{r}} 28,000\right.$; Fig. $\left.5 a\right)$ with antithrombin III (Fig. $5 b$ ), $\alpha_{2}$-antiplasmin (Fig. $5 c$ ), and Cīinhibitor (Fig. $5 e$ ) resulted in the formation of complexes stable in SDS with apparent $M_{\mathrm{r}}$ of $87,000,98,000$, and 145,000 , respectively. These complexes contained approximately one half of the radioactivity, while the other half remained at an $M_{\mathrm{r}}$ of 28,000 . This latter fraction was constant in all SDS-PAGE and seemed to represent inactive ${ }^{125}$ I-Factor XIIf. No complexes that involved ${ }^{125}$ I-Factor XIIf were formed, owing to the incubation of the radiolabeled enzyme with $\alpha_{1}$-antitrypsin (Fig. $5 d$ ) and $\alpha_{2}$-macroglobulin (Fig. $5 f$ ); this is consistent with the kinetic results. Analysis of the mixture formed by the incubation of ${ }^{125}$ I-Factor XIIf with normal plasma indicated that the active label was associated with three bands with $M_{\mathrm{r}}$ of $145,000,98,000$, and 87,000 (Fig. $6 \mathrm{~g}$ ). These bands were identified as complexes involving Factor XIIf and Cī-inhibitor, antithrombin III, or $\alpha_{2}-$ antiplasmin, since their migration patterns were identical to those exhibited by these three purified complexes, which were used as internal standards (Fig. 6, $b-d$ ). Quantitative analysis of four experiments with normal plasma indicated that $74 \pm 11 \%$ (mean \pm 1 SD) of the active enzyme was forming a complex with $C \overline{1}$-inhibitor in this milieu, while $26 \pm 11 \%$ of the label was found in the form of complexes that involved Factor XIIf and both $\alpha_{2}$-antiplasmin and antithrombin III. ${ }^{125}$ I-Factor XIIf was also incubated with the plasma from an individual with hereditary angioedema (Fig. $6 \mathrm{~h}$ ). In this plasma, the fraction of active label associated with the band of $M_{\mathrm{r}} 145,000$ was $42 \pm 12 \%$ ( $n$ $=4$ ), while the fraction associated with the bands of $M_{\mathrm{r}} 98,000$ and 87,000 was $58 \pm 12 \%(n=4)$. When the radiolabeled enzyme was added to hereditary angioedema plasma that had been pretreated with antiserum to $C \overline{1}$-inhibitor, all the active label was found within the bands of $M_{\mathrm{r}} 98,000$ and 87,000 (Fig. $6 i$ ). ${ }^{125} \mathrm{I}$-Factor was then incubated with plasma deficient in $\alpha_{2}$-antiplasmin (Fig. $6 j$ ) or in antithrombin III (Fig. $6 k$ ). In both plasmas, the active label was predominantly associated with the band of $M_{\mathrm{r}} 145,000$ (Fig. 6, $j$ and $k$ ) but a small fraction of ${ }^{125}$ I-Factor XIIf migrated as a species of $M_{\mathrm{r}} 87,000$ in $\alpha_{2}$-antiplasmin-deficient plasma (Fig. $6 j$ ) and as a species of $M_{\mathrm{r}} 98,000$ in antithrombin III-deficient plasma (Fig. $6 k$ ). When ${ }^{125}$ I-Factor XIIf was incubated with plasma deficient in both $\alpha_{2}$-antiplasmin and antithrombin III, the active label was entirely associated with the band of $M_{\mathrm{r}} 145,000$ (Fig. 6, $l$ ). Finally, the requirement for an active enzyme species to observe labeled complexes with $M_{\mathrm{r}}>28,000$ was demonstrated by an experiment in which DFP-treated ${ }^{125}$ I-Factor XIIf was incubated with normal plasma.

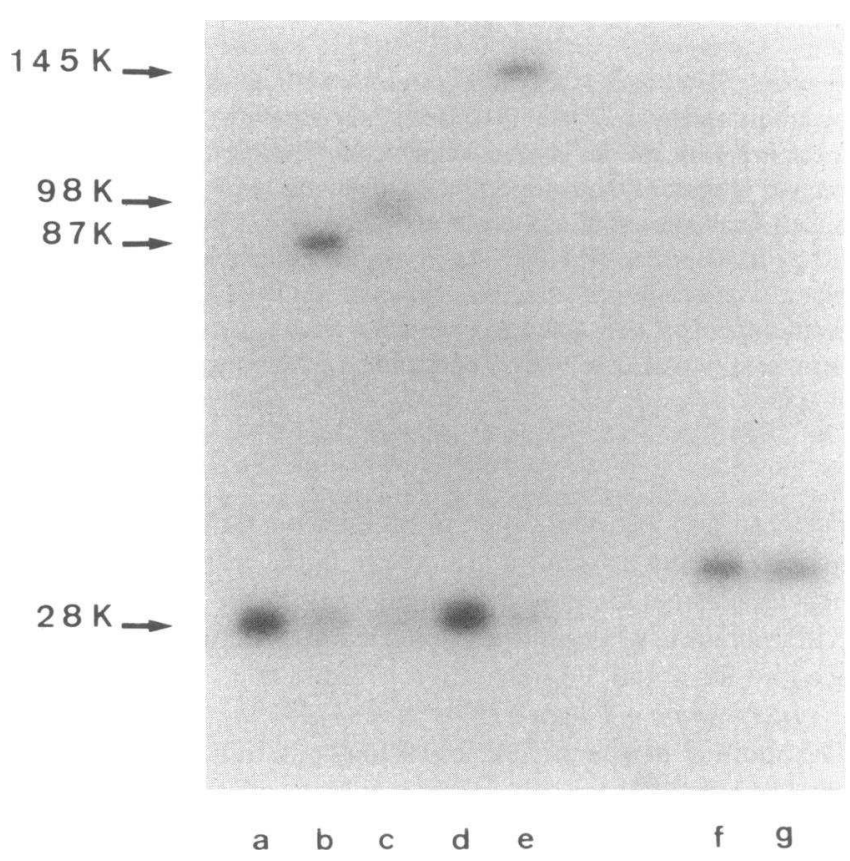

Figure 5. Autoradiogram of SDS-PAGE (10\%) analysis of mixtures resulting from the incubation of ${ }^{125} \mathrm{I}$-Factor XIIf with purified plasma protease inhibitors. Prior to electrophoresis, ${ }^{125}$ I-Factor XIIF (5 ng) was incubated for $2 \mathrm{~h}$ at $37^{\circ} \mathrm{C}$ in a final volume of $35 \mu \mathrm{l}$ with either buffer ( $a$ and $g$ ); $35 \mu \mathrm{g}$ antithrombin III (b); $10 \mu \mathrm{g} \alpha_{2}$-antiplasmin (c); $44 \mu \mathrm{g} \alpha_{1}$-antitrypsin $(d) ; 12 \mu \mathrm{g} C \overline{1}$-inhibitor $(e)$; or $25 \mu \mathrm{g} \alpha_{2}$-macroglobulin $(f)$. Lanes $a-e$ were run under nonreducing conditions; lanes $f-g$ were run under reducing conditions. 


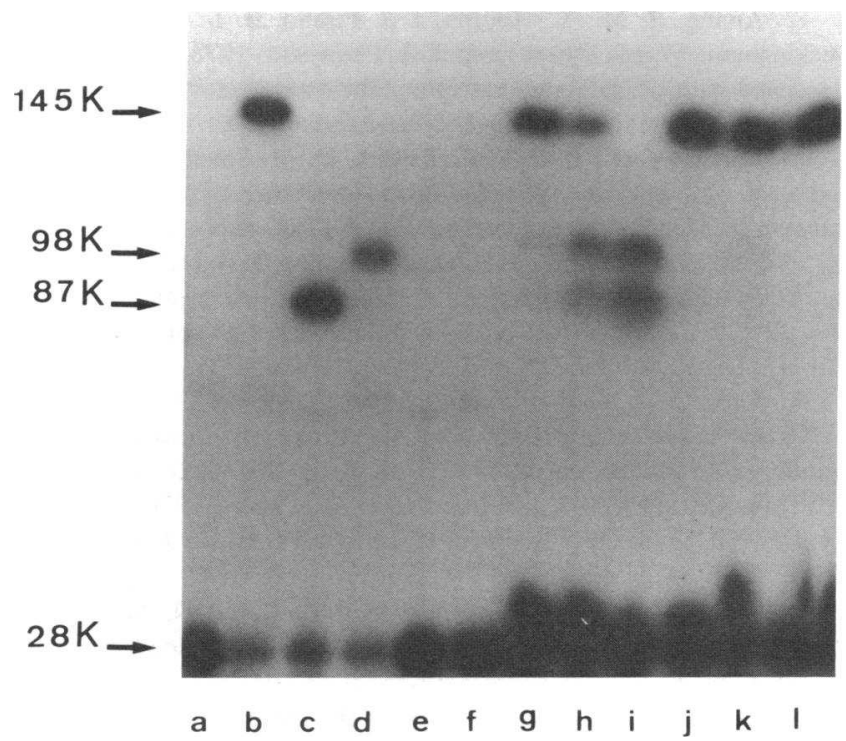

Figure 6. Autoradiogram of SDS-PAGE (8.5\%) analysis of mixtures resulting from the incubation of ${ }^{125}$ I-Factor XIIf with purified plasma protease inhibitors or various plasmas. Before electrophoresis, ${ }^{125} \mathrm{I}$ Factor XIIf was incubated for $2 \mathrm{~h}$ at $37^{\circ} \mathrm{C}$ with the various reagents. Lanes $a-f:{ }^{125} \mathrm{I}$-Factor XIIf $(5 \mathrm{ng})$ and buffer $(a) ; 12 \mu \mathrm{g} C \overline{1}$-inhibitor (b); $35 \mu \mathrm{g}$ antithrombin III (c); $10 \mu \mathrm{g} \alpha_{2}$-antiplasmin (d); $44 \mu \mathrm{g}$ $\alpha_{1}$-antitrypsin (e); and $25 \mu \mathrm{g} \alpha_{2}$-macroglobulin $(f)$. Lanes $g-l:{ }^{125} \mathrm{I}$ Factor XIIf (10 ng in $40 \mu \mathrm{l})$ was incubated with $20 \mu \mathrm{l}$ of either normal plasma $(g)$; hereditary angioedema plasma $(h)$; hereditary angioedema plasma pretreated with an antiserum to $C \overline{1}$-inhibitor $(i) ; \alpha_{2}-$ antiplasmin-depleted plasma $(j)$; antithrombin III-depleted plasma $(k)$; or plasma depleted in both $\alpha_{2}$-antiplasmin and antithrombin III (l). Nonreducing conditions were employed. For quantitative analysis, each lane of the gel was sliced into six sections, $13 \times 8,20 \times 8$, $30 \times 8,34 \times 8,17 \times 8$, and $11 \times 8 \mathrm{~mm}$, respectively. Each section was then counted for radioactivity

In this latter experiment, all of the label was found in a single band of $M_{\mathrm{r}} 28,000$ (not illustrated).

\section{Discussion}

This study indicates that $\mathrm{C} \overline{\mathrm{l}}$-inhibitor is the major inhibitor of Factor XIIf in normal human plasma. This conclusion is supported by $(a)$ the analysis of the kinetics of Factor XIIf inactivation in purified systems and in prekallikrein-deficient plasma, and $(b)$ the quantitation by SDS-PAGE of the Factor XIIfinhibitor complexes formed in various plasma as the result of the inactivation of purified radiolabeled enzyme.

To interpret the behavior of Factor XIIf in plasma, we initially investigated the interaction of Factor XIIf with purified plasma protease inhibitors. The second-order rate constant for the reaction of Factor XIIf and Cí-inhibitor was $18.5 \times 10^{4}$ $\mathrm{M}^{-1} \mathrm{~min}^{-1}$, compared with 0.91 and $0.32 \times 10^{4} \mathrm{M}^{-1} \mathrm{~min}^{-1}$ for the reactions involving Factor XIIf and $\alpha_{2}$-antiplasmin or antithrombin III (Table I). No reaction was detected between the enzyme and plasma concentrations of $\alpha_{1}$-antitrypsin or $\alpha_{2}$-macroglobulin. Thus, on a molar basis, $C \overline{1}$-inhibitor was the most efficient plasma inhibitor of Factor XIIf. Furthermore, the pseudo-first-order rate constants, determined at a normal plasma inhibitor concentration, indicated that $\mathrm{C} \overline{\mathrm{I}}$-inhibitor should account for $>90 \%$ of Factor XIIf inactivation in normal plasma.

The interaction between plasma proteolytic enzymes including Factor XIIf and plasma protease inhibitors results in the formation of enzyme-inhibitor complexes $(16,19,37,38)$. SDS-PAGE analysis of the mixtures resulting from the inactivation of ${ }^{125}$ I-Factor XIIf $\left(M_{\mathrm{r}} 28,000\right)$ by purified $C \overline{1}$-inhibitor $\left(M_{\mathrm{r}} 105,000\right), \alpha_{2}$-antiplasmin $\left(M_{\mathrm{r}} 67,000\right)$, and antithrombin III $\left(M_{\mathrm{r}} 62,000\right)$ demonstrated that radiolabeled complexes, with $M_{\mathrm{r}}$ of $145,000,98,000$, and 87,000 , respectively, were generated during Factor XIIf inactivation (Fig. 5). The $M_{\mathrm{r}}$ of these complexes are in good agreement with the sum of the $M_{\mathrm{r}}$ of the parent molecules, thereby indicating a 1:1 stoichiometry for the reaction between Factor XIIf and the three inhibitors. No labeled complex was formed as a consequence of the incubation of ${ }^{125} I$ Factor XIIf with $\alpha_{1}$-antitrypsin and $\alpha_{2}$-macroglobulin (Fig. 5). These latter observations strengthened our kinetic results as well as those of an earlier report (18), which indicated that Factor XIIf was not inactivated by $\alpha_{1}$-antitrypsin and $\alpha_{2}$-macroglobulin.

Kinetic studies revealed that the rate constant for Factor XIIf inactivation in prekallikrein-deficient plasma was 14.4 $\times 10^{-2} \mathrm{~min}^{-1}$. This constant was in excellent agreement with the expected rate constant $\left(15.5 \times 10^{-2} \mathrm{~min}^{-1}\right)$ calculated using kinetic data derived from the study on the inactivation of Factor XIIf by purified Cī-inhibitor, antithrombin III, and $\alpha_{2}$-antiplasmin (Table I). In addition, the dominant role of $C \overline{1}$-inhibitor in inactivating Factor XIIf in the plasma milieu was demonstrated by the observation that the rate constant for Factor XIIf inactivation by plasma deficient in both $C \overline{1}$-inhibitor and prekallikrein was reduced to $13 \%$ of the rate constant observed when Factor XIIf was inactivated by prekallikrein-deficient plasma (Fig. 4).

The preponderant role of $C \overline{1}$-inhibitor in the inactivation of Factor XIIf in normal plasma was further confirmed by SDSPAGE analysis and autoradiography of mixtures where ${ }^{125} \mathrm{I}$ Factor XIIf had been incubated with various plasmas (Fig. 6). When the radiolabeled enzyme was incubated with normal plasma, it was predominantly inactivated by $C \overline{1}$-inhibitor $(74 \%)$. The difference from the kinetic value of $>90 \%$ probably derives from the 2-h incubation period used, during which the slower inhibitors would have a chance for maximum inactivation. Similar observations were made with analysis of complexes formed between protease inhibitors and kallikrein (39). Moreover, $C \overline{1}$ inhibitor was still inactivating $42 \%$ of the active ${ }^{125}$ I-Factor XIIf in hereditary angioedema plasma, which contained $32 \%$ of the functional Cī-inhibitor of normal plasma. As previously suggested by studies in purified systems (Table I), antithrombin III and $\alpha_{2}$-antiplasmin had a minor role in the inactivation of ${ }^{125} \mathrm{I}$ Factor XIIf in normal plasma (26\%), while they became more important in hereditary angioedema plasma $(58 \%)$. 
Cí-inhibitor is known to be the major plasma inhibitor of the proteolytic enzymes derived from the first component of complement (40) and of plasma kallikrein $(21,39)$, and we now report that $\mathrm{C} \overline{1}$-inhibitor is also the predominant plasma inhibitor of Factor XIIf. Patients who lack Cī-inhibitor suffer from hereditary angioedema (41) and present attacks of mucocutaneous swellings and abdominal pain that are associated with unregulated activation of the classical pathway of the complement system (42) and plasma prekallikrein (43). Since both the first component of complement and plasma prekallikrein can be activated by Factor XIIf, we have suggested that the formation of Factor XIIf could be a central biochemical event for inducing angioedema attacks (43). This suggestion is strengthened by the results of the present report, which demonstrate that $\mathrm{C} \overline{1}$-inhibitor, the missing protein in patients with hereditary angioedema, is also the major plasma inhibitor of Factor XIIf.

\section{Acknowledgments}

This work was supported in part by grants from the Swiss National Science Foundation (3.184.0.82), the National Institutes of Health (HL 24365), and the Council for Tobacco Research (1420).

\section{References}

1. Revak, S. D., C. G. Cochrane, and J. H. Griffin. 1977. The binding and cleavage characteristics of human Hageman factor during contact activation. A comparison of normal plasma with plasmas deficient in Factor XI, prekallikrein, or high molecular weight kininogen. J. Clin. Invest. 59:1167-1175.

2. Dunn, J. T., M. Silverberg, and A. P. Kaplan. 1982. The cleavage and formation of activated human Hageman factor by autodigestion and by kallikrein. J. Biol. Chem. 257:1779-1784.

3. Dunn, J. T., and A. P. Kaplan. 1982. Formation and structure of human Hageman factor fragments. J. Clin. Invest. 70:627-631.

4. Kaplan, A. P., and K. F. Austen. 1971. A prealbumin activator of prekallikrein. II. Derivation of activators of prekallikrein from active Hageman factor by digestion with plasmin. J. Exp. Med. 133:696-712.

5. Revak, S. D., C. G. Cochrane, A. R. Johnston, and T. E. Hugli. 1974. Structural changes accompanying enzymatic activation of human Hageman factor. J. Clin. Invest. 54:619-627.

6. Kaplan, A. P., and K. F. Austen. 1970. A pre-albumin activator of prekallikrein. J. Immunol. 105:802-811.

7. Revak, S. D., C. G. Cochrane, B. N. Bouma, and J. H. Griffin. 1978. Surface and fluid phase activities of two forms of activated Hageman factor produced during contact activation of plasma. J. Exp. Med. 147:719-729.

8. Radcliffe, R., A. Bagdasarian, R. Colman, and Y. Nemerson. 1977. Activation of bovine factor VII by Hageman factor fragments. Blood. 50:611-617.

9. Goldsmith, G. H., Jr, H. Saito, and O. D. Ratnoff. 1978. The activation of plasminogen by Hageman factor (Factor XII) and Hageman factor fragments. J. Clin. Invest. 62:54-60.

10. Donaldson, V. H. 1968. Mechanisms of activation of Cl esterase in hereditary angioneurotic edema plasma in vitro. J. Exp. Med. 127:411429.

11. Ghebrehiwet, B., M. Silverberg, and A. P. Kaplan. 1981. Activation of the classical pathway of complement by Hageman factor fragment. J. Exp. Med. 153:665-676.
12. Alving, B. M., Y. Hojima, J. J. Pisano, B. L. Mason, R. E. Buckingham, M. M. Mozen, and J. S. Finlayson. 1978. Hypotension associated with prekallikrein activator (Hageman-factor fragments) in plasma protein fraction. N. Engl. J. Med. 299:66-70.

13. Van Rosevelt, R. F., J. C. Bakker, D. M. Sinclair, J. Damen, and J. A. Van Mourik. 1982. Bradykinin-mediated hypotension after infusion of plasma-protein fraction. J. Lab. Clin. Med. 100:288-295.

14. Ratnoff, O. D., J. Pensky, D. Ogston, and G. B. Naff. 1969. The inhibition of plasmin, plasma kallikrein, plasma permeability factor, and the Clr subcomponent of the first component of complement by serum Cl esterase inhibitor. J. Exp. Med. 129:315-331.

15. Schreiber, A. D., A. P. Kaplan, and K. F. Austen. 1973. Inhibition by $\mathrm{C}$ îINH of Hageman factor fragment activation of coagulation, fibrinolysis, and kinin generation. J. Clin. Invest. 52:1402-1409.

16. Stead, N., A. P. Kaplan, and R. D. Rosenberg. 1976. Inhibition of activated factor XII by antithrombin-heparin cofactor. J. Biol. Chem. 251:6481-6488.

17. Saito, H., G. H. Goldsmith, M. Moroi, and N. Aoki. 1979. Inhibitory spectrum of $\alpha_{2}$-plasma inhibitor. Proc. Natl. Acad. Sci. USA. 76:2013-2017.

18. Ratnoff, O. D. 1981. Studies on the inhibition of ellagic acidactivated Hageman factor (factor XII) and Hageman factor fragments. Blood. 57:55-58.

19. Revak, S. D., and C. G. Cochrane. 1976. The relationship of structure and function in human Hageman factor. The association of enzymatic and binding activities with separate regions of the molecule. J. Clin. Invest. 57:852-860.

20. Schapira, M., L. D. Silver, C. F. Scott, and R. W. Colman. 1982. New and rapid functional assay for Cì-inhibitor in human plasma. Blood. 59:719-724.

21. Van der Graaf, F., J. A. Koedam, and B. N. Bouma. 1983. Inactivation of kallikrein in human plasma. J. Clin. Invest. 71:149-158.

22. Ouchterlony, O., and L.-A. Nilsson. 1979. Immunodiffusion and immunoelectrophoresis. In Handbook of Experimental Immunology, D. M. Weir, editor. Blackwell Scientific Publications, Oxford. Third edition. 19.1-19.44.

23. Collen, D. 1976. Identification and some properties of a new fast-reacting plasmin inhibitor in human plasma. Eur. J. Biochem. 69:209-216.

24. Schapira, M., C. F. Scott, and R. W. Colman. 1981. Protection of human plasma kallikrein from inactivation by $\mathrm{C} \overline{\mathrm{l}}$-inhibitor and other protease inhibitors. The role of high molecular weight kininogen. Biochemistry. 20:2738-2743.

25. Fisher, C. F., A. H. Schmaier, P. Addonizio, and R. W. Colman. 1982. Assay of plasma prekallikrein: comparison of amidolytic, esterolytic, coagulation, and immunochemical assays. Blood. 59:963-970.

26. Scott, C. F., C. Y. Liu, and R. W. Colman. 1979. Human plasma prekallikrein: a rapid high-yield method for purification. Eur. J. Biochem. 100:77-83.

27. Bolton, A. E., and W. M. Hunter. 1973. The labelling of proteins to high specific radioactivities by conjugation to a ${ }^{125} \mathrm{I}$-containing acylating agent. Application to the radioimmunoassay. Biochem. J. 133:529-539.

28. Reboul, A., G. J. Arlaud, R. B. Sim, and M. G. Colomb. 1977. A simplified procedure for the purification of $\mathrm{C} \overline{1}$-inactivator from human plasma. Interaction with complement subcomponents $C \bar{r} r$ and $C \bar{s}$. FEBS (Fed. Eur. Biochem. Soc.) Lett. 79:45-50.

29. Schapira, M., C. F. Scott, A. James, L. D. Silver, F. Kueppers, H. L. James, and R. W. Colman. 1982. High molecular weight kininogen or its light chain protects human plasma kallikrein from inactivation by plasma protease inhibitors. Biochemistry. 21:567-572. 
30. Lijnen, H. R., M. Hoylaerts, and D. Collen. 1980. Isolation and characterization of a human plasma protein with affinity for the lysine binding sites in plasminogen. Role in the regulation of fibrinolysis and identification as histidine-rich glycoprotein. J. Biol. Chem. 255:1021410222.

31. Wiman, B. 1980. Affinity-chromatographic purification of human $\alpha_{2}$-antiplasmin. Biochem. J. 191:229-232.

32. Chase, T., Jr., and E. Shaw. 1970. Titration of trypsin, plasmin, and thrombin with $p$-nitrophenyl $p^{\prime}$-guanidinobenzoate $\mathrm{HCl}$. Methods Enzymol. 19:20-27.

33. Cohen, A. B., and H. L. James. 1978. Evaluation of alpha-1antitrypsin as a potential therapeutic agent. Proc. Int. Workshop Technol. Protein Separation and Improvement of Blood Plasma Fractionation. H. E. Sandberg, editor. Department of Health, Education, and Welfare Publication No. NIH78-14222. U. S. Government Printing Office, Washington. 326-338.

34. Sottrup-Jensen, L., T. E. Petersen, and S. Magnusson. 1980. A thiolester in $\alpha_{2}$-macroglobulin cleaved during proteinase complex formation. FEBS (Fed. Eur. Biochem. Soc.) Lett. 121:275-279.

35. Kirby, E. P., and P. J. McDevitt. 1983. The binding of bovine factor XII to kaolin. Blood. 61:652-659.

36. Laemmli, U. K. 1970. Cleavage of structural proteins during the assembly of the head of bacteriophage T4. Nature (Lond.). 227:680685.
37. Harpel, P. C. 1982. Blood proteolytic enzyme inhibitors: their role in modulating coagulation and fibrinolytic enzyme pathways. In Hemostasis and Thrombosis. R. W. Colman, J. Hirsch, V. J. Marder, and E. W. Salzman, editors. J. B. Lippincott Co., Philadelphia. 738747.

38. Tankersley, D. L., B. M. Alving, and J. S. Finlayson. 1982. Preparation of $\beta$-XIla (Hageman factor fragment) from human plasma. Thromb. Res. 25:307-317.

39. Schapira, M., C. F. Scott, and R. W. Colman. 1982. Contribution of plasma protease inhibitors to the inactivation of kallikrein in plasma. J. Clin. Invest. 69:462-468.

40. Ziccardi, R. J. 1981. Activation of the early components of the classical complement pathway under physiologic conditions. J. Immunol. 126:1769-1773.

41. Donaldson, V. H., and R. R. Evans. 1963. A biochemical abnormality in hereditary angioneurotic edema. Absence of serum inhibitor of C1-esterase. Am. J. Med. 35:37-44.

42. Donaldson, V. H., and F. S. Rosen. 1964. Action of complement in hereditary angioneurotic edema: the role of C1-esterase. J. Clin. Invest. 43:2204-2213.

43. Schapira, M., L. D. Silver, C. F. Scott, A. H. Schmaier, L. J. Prograis, Jr., J. G. Curd, and R. W. Colman. 1983. Prekallikrein activation and high molecular weight kininogen consumption in hereditary angioedema. N. Engl. J. Med. 308:1050-1053. 